adults in the analysis by Künzli et al. ${ }^{15}$ The authors speculate that they did not find an effect of distance to roadway because their study design was longitudinal, and this variable did not change over time for most subjects. Moreover, they contend that the modelled traffic-related particulate matter exposures which they assigned to their subjects captured the spatial and temporal heterogeneity of individual exposures better than can be achieved with distance to roadway metrics. They suggest that this greater heterogeneity of exposure allowed their analysis to achieve statistical significance despite the relatively small number of new cases of asthma in the SAPALDIA cohort. Similar reasoning can be applied to the study by Jerrett et al which captured spatial heterogeneity in traffic exposures by using nitrogen dioxide concentrations measured immediately outside the children's homes as a proxy for the traffic-related pollution mixture. $^{10}$

Perhaps the greatest research challenge regarding the impact of traffic-related pollution on asthma is to determine what specific constituents of the mixture are responsible for the observed effects. While diesel exhaust particles have clearly been shown to induce both cytotoxic and immune adjuvant responses in toxicological studies $^{16}$ as well as acute lung function decrements in subjects with asthma, ${ }^{17}$ it has been difficult to distinguish diesel effects from those of other components of the traffic mixture in epidemiological studies, largely due to an inability to assess exposure properly. Until we develop better exposure assessment methods, we will be unable to meet this challenge. Without good data about the causative agents in the traffic pollution mixture, our ability to control exposures to protect the health of people with asthma will continue to be handicapped.

Competing interests: None.

Thorax 2009;64:646-647. doi:10.1136/thx.2009.116418

\section{REFERENCES}

1. Bernstein JA, Alexis N, Barnes $\mathrm{C}$, et al. Health effects of air pollution. J Allergy Clin Immunol 2004;114:1116-23

2. Gilbert NL, Goldberg MS, Beckerman B, et al. Assessing spatial variability of ambient nitrogen dioxide in Montreal, Canada, with a land-use regression model. J Air Waste Manag Assoc 2005;55:1059-63.

3. Zhu Y, Hinds WC, Kim S, et al. Concentration and size distribution of ultrafine particles near a major highway. J Air Waste Manag Assoc 2002;52:1032-42.

4. Morris SE, Sale RC, Wakefield JC, et al. Hospita admissions for asthma and chronic obstructive airways disease in east London hospitals and proximity of residence to main roads. J Epidemiol Community Health 2000;54:75-6.

5. Nicolai T, Carr D, Weiland SK, et al. Urban traffic and pollutant exposure related to respiratory outcomes and atopy in a large sample of children. Eur Respir $J$ 2003;21:956-63.
6. van Vliet $\mathbf{P}$, Knape M, de Hartog J, et al. Motor vehicle exhaust and chronic respiratory symptoms in children living near freeways. Environ Res 1997:74:122-32.

7. Venn AJ, Lewis SA, Cooper $\mathrm{M}$, et al. Living near a main road and the risk of wheezing illness in children Am J Respir Crit Care Med 2001;164:2177-80.

8. Zmirou D, Gauvin S, Pin I, et al. Traffic related air pollution and incidence of childhood asthma: results of the Vesta case-control study. J Epidemiol Community Health 2004;58:18-23.

9. McConnell R, Berhane K, Yao L, et al. Traffic, susceptibility, and childhood asthma. Environ Health Perspect 2006;114:766-72.

10. Jerrett M, Shankardass K, Berhane K, et al. Traffic related air pollution and asthma onset in children: a prospective cohort study with individual exposure measurement. Environ Health Perspect 2008;116:1433-8.

11. Salam MT, Islam T, Gilliland FD. Recent evidence for adverse effects of residential proximity to traffic sources on asthma. Curr Opin Pulm Med 2008;14:3-8.

12. Meng YY, Wilhelm M, Rull RP, et al. Traffic and outdoor air pollution levels near residences and poorly controlled asthma in adults. Ann Allergy Asthma Immunol 2007:98:455-63.

13. Lwebuga-Mukasa JS, Oyana T, Thenappan A, et al. Association between traffic volume and health care use for asthma among residents at a USCanadian border crossing point. J Asthma 2004;41:289-304.

14. Balmes JR, Earnest G, Katz PP, et al. Exposure to traffic: lung function and health status in adults with asthma. J Allergy Clin Immunol 2009;123:626-31.

15. Künzli N, Bridevaux PO, Liu L-JS, et al. Traffic-related air pollution correlates with adult-onset asthma among never-smokers. Thorax 2009;64:664-70.

16. Riedl M, Diaz-Sanchez D. Biology of diesel exhaust effects on respiratory function. J Allergy Clin Immunol 2005;115:221-8.

17. McCreanor J, Cullinan P, Nieuwenhuijsen MJ, et al. Respiratory effects of exposure to diesel traffic in persons with asthma. N Engl J Med 2007;357:2348-58.

\title{
Pulmonary infection in Wegener's granulomatosis and idiopathic pulmonary fibrosis
}

\section{Nicholas Kim Harrison}

Friederich Wegener's original paper "On generalised septic vessel disease" suggests he thought it likely there was an infectious cause for the condition which now bears his eponym. ${ }^{1}$ The characteristic pathological features of Wegener granulomatosis (WG) are: a necrotising granulomatous inflammation of the respiratory tract with vasculitis affecting both arteries and veins; focal necrotising glomerulonephritis; and a varying degree of systemic vasculitis-the so-called "Wegener's triad". 2 The granulomatous

Correspondence to: Dr Nicholas Kim Harrison, School of Medicine, Swansea University, Swansea, UK; Kim. Harrison@swansea-tr.wales.nhs.uk inflammation is conspicuous for the absence of any obvious microorganism, although granulomatous infections can sometimes be misdiagnosed as WG. ${ }^{3}$ During the 70 years since Wegener's description there have been some remarkable advances in both the diagnosis and treatment of this condition and in our understanding of its pathogenesis. However, the precise nature of the initiating factor(s) remains elusive.

What we do know is that there is a strong association between WG and the human leucocyte antigen (HLA)DPB1*0401 allele, suggesting that there is an inherited predisposition for the condition. ${ }^{4}$ Interestingly, there is also an association with $\alpha-1$ antitrypsin deficiency. ${ }^{5}$ We also know that virtually all patients who subsequently develop the systemic disease have circulating antineutrophil cytoplasmic antibodies (ANCAs) and these are mainly directed against proteinase-3 (PR3), the so-called "Wegener's autoantigen"-a serine protease which regulates cell proliferation, differentiation and death. ${ }^{6}$ This antibody has proved to be a useful biomarker for the diagnosis of $\mathrm{WG}^{78}$ although less so for the likelihood of relapse. ${ }^{9}$ Furthermore, our increasing knowledge of its biological properties has provided new insights into the pathogenesis of WG. Specifically, whilst PR3 is the target antigen for ANCAs, the observation that elevated levels of PR3 at sites of granulomatous inflammation correlate with increased tumour necrosis factor $\alpha(\mathrm{TNF} \alpha)$ has led to the hypothesis that PR3 is directly involved in the modulation of cytokines associated with an aberrant immune response (see Csernok et a ${ }^{10}$ for a review).

Following tissue injury, increased levels of PR3, released from activated or dying neutrophils, might act as a danger/alarm 
signal interacting with proteinase-activated receptor-2 (PAR-2), the so-called "gateway receptors" on dendritic cells. This would result in their maturation and instruction to initiate an innate $T$ helper 1 (Th1) immune response. However, PR3 also has further effects on inflammation mediated by two distinct actions on interleukin 32 (IL32), a recently identified cytokine which induces production of TNF $\alpha$, IL1 $\beta$, IL6 and 2CXC chemokines by immune cells. ${ }^{10}$ It is known that PR3 activates IL32 by enzymatic cleavage, thereby enhancing its proinflammatory effects. ${ }^{11}$ However, PR3 is also known to be a specific binding protein for IL $32 \alpha$, independently of its enzymatic activity. ${ }^{12}$ It thus has the ability both to activate and to inhibit IL32, and the latter could represent an important negative feedback mechanism designed to limit adverse effects of prolonged inflammation. It therefore follows that inhibition of this feedback, for example by ANCAs, could result in an IL32-mediated, uncontrolled inflammatory reaction which may be relevant to the vasculitis of WG.

Further evidence that PR3-ANCA interactions may be directly related to the pathogenesis of WG comes from a recent in vitro study of human oral, lung and kidney epithelial cells. These cells do not normally secrete proinflammatory cytokines when stimulated with pathogenassociated molecular patterns (PAMPs). However, in the presence of either antiPR3 antibodies or serum from patients with WG, such cells release IL6, IL8, monocyte chemotactic protein-1 (MCP-1) and TNF $\alpha{ }^{13}$ ANCA also causes dysregulated neutrophil apoptosis resulting in increased inflammatory mediator release. ${ }^{14}$

Another, but not yet final, piece of this rather elaborate jigsaw relates to speculation on what might trigger the switch from localised granulomatous inflammation in the upper respiratory tract to the life-threatening systemic vasculitis and, further, what might cause relapse of such vasculitis in patients whose condition has been stabilised with anti-inflammatory treatment.

The report by Richter et al in this issue of Thorax (see page 692) is the first study to investigate the extent to which the lower respiratory tract of patients with WG is colonised by microorganisms. ${ }^{15}$ They compare these patients with both normal healthy volunteers and a group of patients with idiopathic pulmonary fibrosis (IPF). Interestingly, they demonstrate that the lower respiratory tract of patients with WG in relapse or remission (but not at first presentation) are frequently colonised by
Staphylococcus aureus and to a lesser extent other organisms. Their findings are consistent with previous studies which have related relapse rates of WG to nasal carriage of this organism. ${ }^{16}{ }^{17}$ Furthermore, they show by careful, serial bronchoalveolar lavage that this colonisation is transient rather than persistent. It seems unlikely that such colonisation merely relates to structural damage in the lungs since they found no apparent relationship between the presence of $S$ aureus and radiological evidence of bronchiectasis. The authors' preferred explanation comes from their further observation that the lung epithelial lining fluid of patients with WG is rich in IL1 receptor antagonist (IL1Ra), probably generated by IL32 via mechanisms described above. This molecule is known to be permissive of the growth of $S$ aureus as has been noted in patients with acute respiratory distress syndrome (ARDS), ${ }^{18} 19$ supporting a role for a direct relationship between an inflammatory alveolar microenvironment and bacterial growth.

This report therefore provides evidence to support the hypothesis that bacterial colonisation of the lower respiratory tract may trigger a relapse of WG. It is also consistent with the seminal observation by DeRemee that treatment with the antimicrobial trimethoprim/sulfamethoxazole (co-trimoxazole) combination has a beneficial effect on the clinical course of WG, particularly in its localised form..$^{21}$ Finally, it supports the notion that bacteria in the lower respiratory tract may play a wider role as initiators or progression factors in other pulmonary diseases of unknown cause. The inclusion of a group of patients with IPF is of particular interest in this regard.

As its name suggests, IPF remains a disease of unknown aetiology. However, there is accumulating evidence that there may be a link between infections, particularly Epstein-Barr gammaherpesvirus, and at least some cases of lung fibrosis. ${ }^{22}$ The idea that infectious agents contribute to the initiation and/or progression of IPF is not new; indeed considerable effort has been put into the identification of viral DNA in the lungs of patients with IPF, and increasing evidence supports the hypothesis that viral infection may be an important factor. ${ }^{23} 24$

Much less is known about the role of bacteria in this context. By using a group of patients with IPF as a "disease control", the study by Richter et al also provides new evidence for transient bacterial colonisation of the lungs in patients with IPF. It is therefore interesting to speculate whether this may be one, neglected factor, responsible for the alveolar epithelial injury observed in IPF. Certainly, recurrent "microinfections" would be consistent with the observed temporal and spatial heterogeneity of lung fibrosis seen in usual interstitial pneumonia. The observation that a patient with IPF given empirical treatment with co-trimoxazole (for presumed Pneumocystis jiroveci) showed considerable clinical improvement led to a recent, small, pilot study of this antibiotic in patients with pulmonary fibrosis. ${ }^{25}$ The results are encouraging and a bigger trial is currently underway in the UK to examine this observation further.

It is tempting to speculate that in both WG and IPF, co-trimoxazole treatment may exert a beneficial effect by reducing bacterial colonisation and, thereby, halting the, downstream cellular and molecular interactions which ensue. Whatever agent(s) initiate and/or perpetuate these conditions remains elusive. The study by Richter et al is a timely reminder that the complex relationship between microorganisms and the respiratory tract has yet to yield all its secrets.

Competing interests: None.

Thorax 2009;64:647-649. doi:10.1136/thx.2009.115089

\section{REFERENCES}

1. Wegener F. Uber generalisierte septische GefAsserkrankungen. Verh Dtsch Path Ger 1936;29:202-10.

2. Goodman GC, Churg J. Wegener's granulomatosis. Arch Pathol 1954;58:533-53.

3. Harrison NK, Knight RK. Tuberculosis of the nasopharynx misdiagnosed as Wegener's granulomatosis. Thorax 1986:41:219-20.

4. Heckmann M, Holle JU, Arning L, et al. The Wegener's granulomatosis quantitative trait locus on chromosome 6p21.3 as characterised by tag SNP genotyping. Ann Rheum Dis 2008;67:972-9.

5. Mahr AD, Neogi T, Merkel PA. Epidemiology of Wegener's granulomatosis: lessons from descriptive studies and analyses of genetic and environmental risk determinants. Clin Exp Rheumatol 2006;24(2 Suppl 41):S82-91.

6. Jenne DE, Tschopp J, Ludemann J, et al. Wegener's autoantigen decoded. Nature 1990;346:520.

7. Van der Woude FJ, Rasmussen N, Lobatlo S, et al. Autoantibodies against neutrophils and monocytes: tools for diagnosis and marker of disease activity in Wegener's granulomatosis. Lancet 1985;i:425-9.

8. Finkielman JD, Lee AS, Hummel AM, et al. ANCA are detectable in nearly all patients with active severe Wegener's granulomatosis. Am J Med 2007; 120:643.e9-14.

9. Finkielman JD, Merkel PA, Schroeder D, et al. Antiproteinase 3 antineutrophil cytoplasmic antibodies and disease activity in Wegener granulomatosis. Ann Intern Med 2007;147:611-9.

10. Csernok E, Holle JU, Gross WL. Proteinase 3, protease-activated receptor-2 and interleukin-32: linking innate and autoimmunity in Weger's granulomatosis. Clin Exp Rheumatol 2008;26(Suppl 49):S112-7.

11. Sugawara S. Immune functions of proteinase 3. Crit Rev Immunol 2005;25:343-60.

12. Novick D, Rubinstein M, Azam T, et al. Proteinase 3 is an IL-32 binding protein. Proc Natl Acad Sci USA 2006;103:3316-21. 
13. Uehara A, Hirabayashi Y, Takada H. Antibodies to proteinase 3 prime human oral, lung and kidney epithelial cells to secrete proinflamatory cytokines upon stimulation with agonists to various Toll-like receptors, NOD1, and NOD2. Clin Vaccine Immunol 2008;15:1060-6.

14. Harper L, Ren Y, Savill J, et al. Antineutrophil cytoplasmic antibodies induce reactive oxygendependent dysregulation of primed neutrophil apoptosis and clearance by macrophages. Am J Pathol 2000;157:211-20.

15. Richter A, Stockley RA, Harper L. Pulmonary infection in Wegener's granulomatosis and idiopathic pulmonary fibrosis. Thorax 2009;64:692-7.

16. Pinching AJ, Rees AJ, Pussell BA, et al. Relapses in Wegener's granulomatosis: the role of infection. $B M J$ 1980;281:836-8.
17. Stegeman CA, Tervaert JW, Sluiter WJ, et al. Association of chronic nasal carriage of Staphylococcus aureus and higher relapse rates in Wegener's granulomatosis. Ann Intern Med 1994:120:12-4.

18. Meduri GU, Kanganat S, Stefan E, et al. Cytokines IL-1 beta, IL-6 and TNF alpha enhance in vitro growth of bacteria. Am J Respir Crit Care Med 1999:160:961-7.

19. Kanangat S, Bronze MS, Meduri GU, et al. Enhanced extracellular growth of Staphylococcus aureus in the presence of selected linear peptide fragments of human interleukin (IL)-1 beta and IL-1 receptor antagonist. J Infect Dis 2001;183:65-9.

20. DeRemee R, McDonald TJ, Weiland LH. Wegener's granulomatosis: observations on treatment with antimicrobial agents. Mayo Clin Proc 1985;60:27-32.

21. DeRemee R. The treatment of Wegener's granulomatosis with trimethoprim/ sulphamethoxazole: illusion or vision? Arth Rheum 1988;31:1068-72.

22. Vannella $\mathbf{K M}$, Moore BB. Viruses as co-factors for the initiation or exacerbation of lung fibrosis.

Fibrogenesis Tissue Repair 2008;1:2

23. Stewart JP, Egan JJ, Ross AJ, et al. The detection of Epstein-Barr virus DNA in lung tissue from patients with idiopathic pulmonary fibrosis. Am J Respir Crit Care Med 1999;159:1336-41.

24. Tang YW, Johnson JE, Browning PJ, et al Herpesvirus DNA is consistently detected in lungs of patients with idiopathic pulmonary fibrosis. J Clin Microbiol 2003;41:2633-40.

25. Varney VA, Parnell HM, Salisbury DT, et al. A double blind randomized placebo controlled pilot study of oral co-trimoxazole in advanced fibrotic lung disease. Pulm Pharmacol Ther 2008;21:178-87.

\section{Where there's smoke... there's tuberculosis}

\section{Stephen Gordon, Jamie Rylance}

Recent observations have demonstrated precisely the increased life expectancy associated with clean environmental air in the USA. ${ }^{1}$ This dramatic health benefit has been achieved at levels of pollution very much lower than those found indoors in underdeveloped countries. Traditional cooking fires using biomass (organic material) fuel are inefficient and the smoke levels measured in poorly ventilated homes are often 100 times that regarded as dangerous in the affluent industrial world. High levels of indoor air pollution have been associated in epidemiological studies with upper and lower respiratory tract acute infections (ALRIs), chronic obstructive pulmonary disease (COPD) and lung cancer. ${ }^{2}$ There has been less evidence to support an association of indoor air pollution with biomass fuel use and tuberculosis, and so the report by Kolappan and Subramani (see page 705) in this issue is most welcome.

Three billion people use biomass fuel globally, almost entirely in areas with high rates of tuberculosis. The confounding effects of poverty, crowding, malnutrition and increased exposure make an association between biomass fuel use and tuberculosis very hard to dissect. In a well-conducted study in Chennai, India, the authors report that $36 \%$ of proven tuberculosis cases can be associated with biomass fuel usage. Confounding factors including cigarette smoking, alcohol use, socioeconomic status and case-contact are

Correspondence to: Dr Stephen Gordon, Liverpool School of Tropical Medicine, Pembroke Place, Liverpool L3 50A, UK; sbgordon@liverpool.ac.uk also examined. This study is likely to underestimate the true burden of tuberculosis transmission as young children are intensely exposed to biomass smoke in the home and are a very difficult group in which to diagnose tuberculosis.

Given the association of ALRIs with biomass smoke exposure, and the association of cigarette smoking with tuberculosis, the finding of this study is not surprising. Two major unanswered questions are immediately provoked. First: what is the mechanism behind this association? Secondly: what can be done to protect biomass smoke-exposed adults and children in areas with high tuberculosis transmission?

The mechanism by which biomass smoke exposure results in increased tuberculosis disease is likely to relate to established effects on alveolar macrophages and pulmonary epithelium. Smoke particle size, form and surface chemistry initially promote a proinflammatory state and oxidative damage to the lung. Laboratory models have demonstrated upregulation of tumour necrosis factor $\alpha$ (TNF $\alpha$ ), interleukin 6 (IL6) and IL8, nuclear factor- $\kappa \mathrm{B}(\mathrm{NF}-\kappa \mathrm{B})$ activation and cellular lipid peroxidation. Apoptosis of alveolar macrophages is also increased, and, although this is usually considered a positive host defence response, cytotoxic effects may predominate. Phagocytosis is reduced in some non-tuberculosis bacterial studies, and pulmonary mycobacterial load is increased by diesel exhaust participates. Peak respiratory burst activity may be decreased, but inducible nitric oxide synthase (iNOS) expression is upregulated. There is no clear narrative to this disruption, and many as yet uninvestigated possibilities. As the epidemiological evidence becomes stronger, there is a need to strengthen mechanistic explanations using relevant in vitro models of biomass particulates.

More importantly to the 7 million people per year who are diagnosed as having tuberculosis in underdeveloped countries, what can be done to prevent this burden of disease? The answer here can be stated with more certainty. Multiple new technologies exist to improve fuel efficiency and domestic ventilation, even in the most resourcedeprived situations (www.hedon.info). At the Partnership for Clean Indoor Air Forum in Kampala in March 2009 (www.pciaonline.org), 265 non-governmental organisations (NGOs) re-asserted their intention to improve indoor air quality not only because of the environmental imperative to do so, but also because of the probable health benefits of improved stove technology.

As chest physicians, we look forward to the results of the RESPIRE trial from Guatemala, due to be published this year, which is expected to show for the first time a direct health benefit from an indoor air intervention. A stove intervention alone, however, will not reduce the global burden of tuberculosis.

Reducing biomass smoke-related disease will require multifaceted action to improve fuel security, health education (particularly for women), diet and environmental conservation coupled with excellent tuberculosis case management. These are exciting and challenging times.

Competing interests: None.

Thorax 2009;64:649-650. doi:10.1136/thx.2009.116400

\section{REFERENCES}

1. Pope CA 3rd, Ezzati M, Dockery DW. Fine-particulate air pollution and life expectancy in the United States. N Engl J Med 2009;360:376-86. 